Research Paper:

\title{
Discharge Against Medical Advice in Teaching Hospitals: crossuart A Telephone Survey
}

\author{
${\text { Majid Heydari }{ }^{1} \text {, Omid Khosravizadeh }}^{2}$, Rohalah Kalhor ${ }^{2}$, Marziye Sharifi', Azadeh Ahmadzadeh Ghasab ${ }^{3 *}$
}

1. Department of Health Services Management, School of Health Management and Information Sciences, Iran University of Medical Sciences, Tehran, Iran 2. Social Determinants of Health Research Center, Qazvin University of Medical Sciences, Qazvin, Iran.

3. Department of Health Management and Economics, School of Public Health, Tehran University of Medical Sciences, Tehran, Iran.

\begin{tabular}{|l|l|}
\hline $\begin{array}{c}\text { Use yur devic to scan } \\
\text { and read thearticle online }\end{array}$ & $\begin{array}{l}\text { Citation: Heydari, M., et al., 2017. Discharge Against Medical Advice in Teaching Hospitals: A Telephone Survey. Journal } \\
\text { of Client-Centered Nursing Care, 3(4), pp. 277-282. https://doi.org/10.32598/jccnc.3.4.277 }\end{array}$ \\
dol: $:$ https://doi.org/10.32598/jccnc.3.4.277
\end{tabular}

Article info:

Received: 10 May 2017

Accepted: 27 Sep 2017

Keywords:

Patient discharge,

Medical advice, Teaching hospital

\begin{abstract}
A B S T RA C T
Background: Discharge with personal consent is considered as one of the main problems in hospitalization condition since many patients leave the hospital prematurely against the doctor's advice. Thus, the aim of this study was to identify the factors affecting the discharge with personal satisfaction in selected teaching hospitals of Tehran University of Medical Sciences.

Methods: The present study was a descriptive and cross-sectional analysis that was carried out on patients discharged with personal satisfaction from selected training hospitals of the Tehran University of Medical Sciences in 2016. The sample size was 153 patients who were randomly selected from Sina, Shariati and specialized women hospitals. The data were collected through using a self-made checklist and telephone interview. The SPSS V. 18 software and statistical tests such as Chi-square and t-test were used for data analysis.
\end{abstract}

Results: The most common causes of patient's discharge with personal satisfaction was personal issues related to the sick and the highest among these causes was patient recovery. The least common causes of discharge with personal satisfaction was related to the hospital. There was no significant link of gender, age, place and insurance type with personal discharge, but there was a significant link between the discharges of the hospital with own agreement and type of the hospital $(\mathrm{P}<0.05)$.

Conclusion: Hospital staff education, motivating the staff to participate actively in obtaining consent from patients and informing the patients about the stage of their treatment and recovery should be considered as priority management activities.

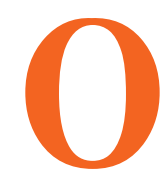

\section{Background}

ne of the factors causing patient dissatisfaction is discharge with personal satisfaction, which ultimately leads to reduced number of patients and poor financial situation of centers and has done irreparable damage to hospitals (Vahdat, Hesam \& Mehrabian 2010). Discharge with personal satisfaction or discharge against medical advice is one of the main problems in terms of hospitalization condition, and it

\section{* Corresponding Author:}

Azadeh Ahmadzadeh Ghasab, PhD

Address: Department of Health Management and Economics, School of Public Health, Tehran University of Medical Sciences, Tehran, Iran. Tel: +98 (936) 4898088

E-mail: azade.ah67@gmail.com 
occurs when a patient leaves the hospital against the doctor's advice (Kalburgi, Cady \& McClymont 2016). This can affect the disease and increase the risk of readmission to hospital. Discharge with personal satisfaction is the strongest factor of readmissions in the 15 first days after leaving the hospital, and $21 \%$ of people with personal satisfaction from the hospital were hospitalized again.

Many of the investigation results suggest that this is because of the sensitivities in the patients' expectations, the hospital staff's lack of knowledge and lack of understanding of their patients' expectations, and the amount of annual government spending and heavy duties (Alfandre 2014). Some hospitals withdraw from their work due to the high costs and economic losses, but this number is little in comparison with the hospitals that are working despite discontent and reduced bed occupancy rate (Naderi et al. 2014). The need of discharged patients with personal satisfaction can be generally categorized into the following three areas: 1. Basic needs that are generally linked to the origin of the main mission of the organization; 2. Clinical services; and 3. Health care. The need is related to how to provide services (performance), including waiting time, handling and motivational needs related to customer needs, forecasting techniques, customer service program to patients and their security (Macrohon 2012).

Many studies indicate that the study of patient satisfaction and their influencing factors are tools for raising the quality of services. Patient satisfaction on how to provide services not only increases his/her loyalty to the organization, but can also encourage others to use its services (Saravi et al. 2013). The factors that could affect patient satisfaction and personal discharge can be linked to three categories: relevant factors to hospital care systems, factors associated with the characteristics of the patient and factors associated with the clinical characteristics. Complete and timely discharge of the patients' therapy process can reduce readmissions of the patients, which can reduce the use of resources and prevent affecting the cost (Greenwald, Denham \& Jack 2007). Several studies have been conducted on this issue in Iran (Malekzadeh et al. 2016; Hadadi et al. 2016) and other countries (Jeong et al. 2016; Ismail, Mohamad, \& Che'Man 2016; Martenstein, Plinkert \& Wienke 2016).

It is important to note that the lack of completing the hospitalization process is considered as a risk factor in disease recurrence, hospital readmissions, and more spending for the patient (Southern, Nahvi \& Arnsten 2012). Identifying the variables related to discharge with personal agreement is essential. In this regard, the aim of the present study was to investigate the reasons for patients in announcing the satisfaction for discharge from hospital against the recommendations of the hospital's medical subsidiaries of Tehran University of Medical Sciences in 2016.

\section{Materials and Methods}

It was a descriptive, cross-sectional study which was carried out in the teaching hospitals of the Tehran University of Medical Sciences in 2016. Research population included discharged patients with personal consent in selected teaching hospital of Tehran University of Medical Sciences in 2016. The sample size estimated 138 using Cochran formula. Due to the possibility of collapse of the sample volume during the study, another 15 patients were added to the sample volume. Eventually, 153 people were randomly selected from Sina and Shariati general hospitals (each 50 people) and Women's Comprehensive Hospital (53 people) affiliated to the Tehran University of Medical Sciences.

The data were extracted via telephone interview based on the phone number of patients from their medical records. The data were gathered with the use of a checklist including four parts (causes related to the patient's own issues; causes related to hospital staff; causes related to hospital and demographic and background information including gender, age, history of admission to hospital sector, etc.; and insurance type). The factors were measured on a two-point scale that included yes and no responses. The validity of the checklist was confirmed by experts in two stages, and its reliability was confirmed by the Cronbach's Alpha coefficient $(\alpha=0.82)$. Finally, the data were entered in SPSS-PC 18 software and analyzed with statistical descriptive and analytical tests of Chi-Square and T test at a significance level of 0.05. This study was approved by the ethics committee of the Tehran University of Medical Sciences with ethical code of Tums/19843. There were no limitations to collecting information.

\section{Results}

The results of this study are summarized in four tables. Table 1 shows how the isolated patients are distributed in the hospitals; there were 103 male and 50 female patients in total. Also, this study shows the distribution of patients in the hospitals. Most (62.2\%) of the studied patients were in the age range of 21-40 years.

The study shows that the maximum number of patients in the emergency department was $58.5 \%$, and the lowest 
Table 1. Demographic characteristics of patients in the selected hospitals

\begin{tabular}{|c|c|c|c|c|c|c|c|c|c|c|c|c|c|c|c|c|}
\hline \multirow{3}{*}{$\begin{array}{l}\text { Name of Hos- } \\
\text { pitals }\end{array}$} & \multirow{2}{*}{\multicolumn{2}{|c|}{$\begin{array}{c}\text { Contribution } \\
\text { of Hospital }\end{array}$}} & \multicolumn{4}{|c|}{ Sex } & \multicolumn{10}{|c|}{ Age Group } \\
\hline & & & \multicolumn{2}{|c|}{ Man } & \multicolumn{2}{|c|}{ Woman } & \multicolumn{2}{|c|}{$<20$} & \multicolumn{2}{|c|}{$21-40$} & \multicolumn{2}{|c|}{$41-60$} & \multicolumn{2}{|c|}{$61-80$} & \multicolumn{2}{|c|}{$>80$} \\
\hline & $\mathbf{N}$ & $\%$ & $\mathbf{N}$ & $\%$ & $\mathbf{N}$ & $\%$ & $\mathbf{N}$ & $\%$ & $\mathbf{N}$ & $\%$ & $\mathbf{N}$ & $\%$ & $\mathbf{N}$ & $\%$ & $\mathbf{N}$ & $\%$ \\
\hline Sina & 50 & 32.7 & 30 & 19.6 & 20 & 13.1 & 5 & 3.3 & 22 & 41.4 & 8 & 5.2 & 13 & 8.5 & 2 & 1.3 \\
\hline $\begin{array}{l}\text { Women's Com- } \\
\text { prehensive }\end{array}$ & 53 & 34.6 & -- & --- & 53 & 34.6 & 1 & 0.7 & 52 & 34 & -- & -- & -- & --- & -- & --- \\
\hline Shariati & 50 & 32.7 & 20 & 13.1 & 30 & 19.6 & 4 & 2.6 & 21 & 13.7 & 13 & 8.5 & 11 & 7.2 & 1 & 0.7 \\
\hline Total & 153 & 100 & 50 & 32.7 & 103 & 67.3 & 10 & 6.5 & 95 & 62.1 & 21 & 13.7 & 24 & 15.7 & 3 & 2 \\
\hline
\end{tabular}

number was in the nephrology and CCU with $0.7 \%$ each (Table 2). The study also showed that the most common personal discharge issues were related to the patients, i.e. feeling recovery in the patient. The lowest cause of personal discharge was related to the hospital, i.e. poor nutrition and absence of empty bed (Table 3).

Finally, Table 4 shows the relationship between the background variables and the discharge of the patients with personal consent. It shows that there is no significant relationship between gender, age, place and insurance type with links to discharge with personal consent, but there is a significant relationship between the dis- charge of the hospital with personal agreement and type of hospital.

\section{Discussion}

The findings suggest that most of the people with personal satisfaction who left the hospital were females aged 21-40 years. Among the different hospital departments, the emergency department had the most number of people with discharge with personal consent. In terms of insurance, most of the patients discharged with a personal consent had social insurance. It was also determined that the most common causes of discharge were related to patient issues while the

Table 2. Frequency of types of wards in selected hospitals

\begin{tabular}{|c|c|c|c|c|c|c|c|c|}
\hline \multirow{2}{*}{ Ward } & \multicolumn{2}{|c|}{ Shariati } & \multicolumn{2}{|c|}{ Women's Comprehensive } & \multicolumn{2}{|c|}{ Sina } & \multicolumn{2}{|c|}{ Total } \\
\hline & $\%$ & $\mathbf{N}$ & $\%$ & $\mathbf{N}$ & $\%$ & $\mathbf{N}$ & $\%$ & $\mathbf{N}$ \\
\hline Emergency & 15.7 & 24 & 12.4 & 19 & 3.7 & 47 & 58.8 & 90 \\
\hline Surgery & --- & --- & 15 & 23 & 2 & 3 & 17 & 26 \\
\hline Obstetric & 0.7 & 1 & 7.2 & 11 & --- & --- & 7.8 & 12 \\
\hline Internal & 2.6 & 4 & -- & --- & -- & --- & 2.6 & 4 \\
\hline Lung & 2 & 3 & -- & --- & --- & --- & 2 & 3 \\
\hline Cat lab & 1.3 & 2 & --- & --- & --- & --- & 1.3 & 2 \\
\hline Nephrology & 0.7 & 1 & -- & --- & --- & --- & 0.7 & 1 \\
\hline Gland & 1.3 & 2 & --- & --- & --- & --- & 1.3 & 2 \\
\hline $\mathrm{CCU}$ & 0.7 & 1 & --- & --- & --- & --- & 0.7 & 1 \\
\hline Women & 5.2 & 8 & --- & --- & --- & --- & 5.2 & 8 \\
\hline Orthopedic & 2.6 & 4 & --- & --- & --- & --- & 2.6 & 4 \\
\hline Total & 32.7 & 50 & 34.6 & 53 & 32.7 & 50 & 100 & 153 \\
\hline
\end{tabular}


Table 3. Frequency of the causes of discharge against medical advice

\begin{tabular}{|c|c|c|c|c|c|}
\hline Cause & Factors & Sina & Women's Comprehensive & Shariati & Total \\
\hline \multirow{8}{*}{ 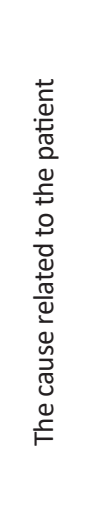 } & Economic condition of patient & 11 & 3 & 3 & 20 \\
\hline & Family dependence & 1 & 5 & --- & 6 \\
\hline & Patient job & 1 & 2 & 2 & 5 \\
\hline & Fear of treatment & --- & 6 & 4 & 10 \\
\hline & Lack of accompany & 9 & 2 & --- & 11 \\
\hline & Recovery feeling & 19 & 8 & 16 & 43 \\
\hline & Long distance & 4 & 4 & 1 & 9 \\
\hline & Fatigue from hospital environment & 3 & 17 & 10 & 30 \\
\hline \multirow{4}{*}{ 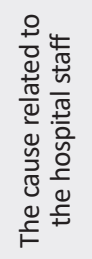 } & Lack of physician check & 14 & 6 & 3 & 23 \\
\hline & Inappropriate contact of personnel & 1 & 2 & --- & 3 \\
\hline & Lack of timely presence of physician & 1 & 4 & --- & 5 \\
\hline & Lack of work control of physician and nurses & 11 & 2 & --- & 13 \\
\hline \multirow{6}{*}{ 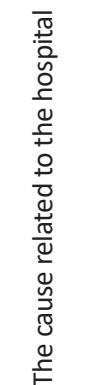 } & Inappropriate cleaning & 1 & --- & --- & 1 \\
\hline & Inappropriate equipment & 1 & --- & 3 & 4 \\
\hline & Inappropriate nutrition & --- & --- & --- & --- \\
\hline & Inappropriate environment & 6 & 2 & 3 & 11 \\
\hline & Cancel surgery & --- & --- & 2 & 2 \\
\hline & Not empty bed & -- & --- & --- & --- \\
\hline
\end{tabular}

minimum number of causes was related to hospital situation. Among the causes related to the patient, the most common causes were feeling recovery in the patient, tired of the hospital environment and prolonged patient treatment, economic situation, a lack of treatment of patients with fear, far-away distance from the hospital, and patient's and family's jobs.
Among the causes related to the hospital staff, taking care of the doctors and nurses are the most common cause of leaving the hospital. Among the causes of regarding the status of the hospital, the most common cause was hospital environment. In this category, none of the patients mentioned poor nutrition and empty beds as reasons for discharge with personal consent. In total, the sick feeling, recovery from the environment and prolonged

Table 4. Relationship between the background variables and discharge against medical advice

\begin{tabular}{ccc}
\hline Variable & Test & Significant Level \\
\hline Sex & -0.401 & 0.689 \\
\hline Hospital & 19.60 & 0.001 \\
\hline Age & 5.70 & 0.223 \\
\hline Ward of hospital & 9.60 & 0.383 \\
\hline Type of insurance & 10.88 & 0.208 \\
\hline
\end{tabular}


hospital treatment, and care by doctors and nurses were the main reasons for discharge from the hospital.

In the Bastani's study at the Tehran University of Medical Sciences in 2010, the most common reason for patients leaving the hospital was in connection with the patient's issues (77\%), i.e. relative improvement from the patient's view, distance of the hospital from residence, and fatigue and exhaustion from the hospital environment because of the long course of treatment (Bastani 2010). Their results are consistent with our findings. In the study by Rangraz in the Kashan University of Medical Sciences in 2008, the biggest issues related to discharge with personal agreement were related to the patients' issues (61\%) (Rezaeiimofrad 2010); these results are also similar to the results of our present study. In the Vahdat's study, the main reasons for the discharge of patients with personal satisfaction, were dissatisfaction with the medical services $(33 \%)$, doctors' proposal $(27.5 \%)$ and dissatisfaction with the facilities and equipment $(12.7 \%)$. He also reported that $59.3 \%$ of under section and $23 \%$ from the emergency department were the highest in the discharge with personal consent (Vahdat, Hesam \& Mehrabian 2010).

In the current study, the emergency department had the highest number of patient discharge with personal satisfaction that complies with the unity of Vahdat's study. In another study, feeling better was reported by $43 \%$ patients and financial problems by $94 \%$ patients as the reasons for discharge with personal satisfaction (Rezaeiimofrad 2010); in our study, feeling better is the most common cause for patient discharge. In the study by Sayitz, the main factors for discharge with personal satisfaction in the United States were lack of insurance and inappropriate economic situation (Hwang 2003).

The study results of Hong Toronto Mitchell hospital also suggest that $28 \%$ of patient discharge with personal consent was because of medical staff and personal problems or family problems; feeling better enough to leave the hospital, feeling uniformity, bored and fatigue of the hospital environment, and dislike for hospital space were mentioned as the other reasons for discharge with personal consent (Hwang 2003). In their study, Jackson has concluded that the behaviors of doctors and nurses not only generates cooperation among the patients but also provides incentive for patients to recommend others to a particular hospital. Our study mentioned that taking care of patients by doctors and nurses is one of the three main reasons that shows a special attention on the subject (Jackson, Chamberlin \& Kroenke 2001). In the study by Jermianiz, as well as the dissatisfaction of health screen- ing measures in $2.2 \%$ of cases, with expressed the patients discharge personal consent (Jeremiah, O'Sullivan $\&$ Stein 1995).

Among the variables in the field, gender, age, kind of insurance, and hospitalization sector, a significant relationship with the discharge of personal desire was observed $(\mathrm{P}>0.05)$. A significant relationship was observed between the types of hospitals and personal discharge $(\mathrm{P}<0.01)$. In the study by Rangraz, significant differences were observed in gender of patients that had consented due to problems with the hospital staff ( $\mathrm{P}<$ 0.03) (Rezaeiimofrad 2010). In this regard, the present study is consistent with the mentioned study.

In Kavoosi's study, a significant relationship was observed between the state of insurance variables $(\mathrm{P}=$ $0.001)$ and the type of health sector $(\mathrm{P}<0.05)$ and the patient's discharge. The number of patients in emergency department and those without insurance who left the hospital was significantly higher than all other patients with personal consent (Kavosi 2012). There was no correspondence between the results of this study with our results in which we showed that a significant relationship does not exist between gender and insurance policy to personal discharge. Nikpour, in a survey of patient satisfaction, came to the conclusion that with the increase in hospitalization days, patient satisfaction was reduced and that no significant differences were observed between patients with insurance and without insurance (Nikpour 2010). In the present study, the results showed that prolonged treatment period is the second factor for discharge with personal consent and that insured social security was the most common reason for discharge with personal consent. The results mentioned in this research have been confirmed more or less in other studies.

Managers, along with medical personnel, need to obtain patients' satisfaction in hospitals and improve their quality of service. Training the hospital staff and motivating them to participate actively in generating satisfaction of the patients and informing them about their treatment and recovery are included as the top priorities for hospital management. It can be said that upgrading of the quality of medical services and health facilities can help create a pleasant environment for patients and, eventually, reduce clearance discharge rate with personal consent.

\section{Acknowledgments}

This study was supported by the Tehran University of Medical Sciences. The authors sincerely appreciate 
all the efforts of individuals who helped us in any way for this study.

\section{Conflict of Interest}

The authors declare that they have no conflict of interest.

\section{References}

Alfandre, D., 2014. Reconsidering against medical advice discharges. Journal of General Internal Medicine, 29(5), p. 706. [DOI:10.1007/s11606-014-2804-2]

Bastani, P., 2012. The causes of discharge against medical advice in teaching \& madical Shohadaye Tajrish center. Paper presented at The First Congress on Clinical Governance and Continuous Quality Improvement. 2012 May 16; Tabriz, Iran.

Greenwald, J. L., Denham, C. R. \& Jack, B. W., 2007. The hospital discharge. Journal of Patient Safety, 3(2), pp. 97-106. [DOI:10.1097/01.jps.0000236916.94696.12]

Hadadi, A. et al., 2016. Discharge against medical advice from a Tehran emergency department. International Journal of Health Care Quality Assurance, 29(1), pp. 24-32. [DOI:10.1108/IJHCQA-03-2015-0030]

Hwang, S. W., et al., 2003. What happens to patients who leave hospital against medical advice. Canadian Medical Association Journal, 168(4), pp. 417-20. PMCID: PMC143546 [PMID] [PMCID]

Ismail, A. K., Mohamad, A. \& Che'Man, Z., 2016. Factors associated with discharge against medical advice from emergency department, Universiti Kebangsaan Malaysia Medical Centre. Medicine \& Health, 11(1), pp. 29-37. [DOI:10.17845/ MH.2016.1101.05]

Jackson, J. L., Chamberlin, J. \& Kroenke, K., 2001. Predictors of patient satisfaction. Social Science \& Medicine, 52(4), pp. 60920. [DOI:10.1016/S0277-9536(00)00164-7]

Jeong, J. et al., 2016. The association between acute alcohol consumption and discharge against medical advice of injured patients in the ED. The American Journal of Emergency Medicine, 34(3), pp. 464-8. [DOI:10.1016/j.ajem.2015.11.065]

Jeremiah, J., O'Sullivan, P. \& Stein, M. D., 1995. Who leaves against medical advice. Journal of General Internal Medicine, 10(7), pp. 403-5. [DOI:10.1007/BF02599843]

Kalburgi, S., Cady, R. \& McClymont, S., 2016. Development of a clinical algorithm for threatened discharge against medical advice. Pediatrics, 137(3), p. 330A. [DOI:10.1542/peds.137. Supplement_3.330A]

Kavosi, Z., et al., 2012. Factors affecting discharge against medical advice in a teaching hospital in Shiraz, Iran. Infornatic Health Management, 9, pp. 448-56.

Macrohon, B. C., 2012. Pediatrician's perspectives on Discharge Against Medical Advice (DAMA) among pediatric patients: A qualitative study. BMC Pediatrics, 12(1). [DOI:10.1186/14712431-12-75]
Malekzadeh, R., et al., 2016. Causes of discharge against medical advice in hospitals affiliated with Mazandaran university of medical sciences, 2014. Journal of Mazandaran University of Medical Sciences, 26(140), pp. 95-102.

Martenstein, I., Plinkert, A. S. \& Wienke, A., 2016. Cave in case of premature discharge against medical advice. $\mathrm{HNO}, 64(3)$, pp. 184-5. [DOI:10.1007/s00106-015-0116-4]

Naderi, S. et al., 2014. Patients in a private hospital in India leave the emergency department against medical advice for financial reasons. International Journal of Emergency Medicine, 7(1), p. 13. [DOI:10.1186/1865-1380-7-13]

Nikpour A., 2010. [Servey of Satisfaction after discharge from affiliated hospitals to Tehran University of Medical Sciences (Persian)] [MSc. thesis]. Tehran: Tehran University of Medical Sciences.

Rezaeiimofrad, M., 2010. Patients' reasons for discharge against medical advice in university hospitals of Kashan university of medical sciences in 2008. Hakim Research Journal, 13(1), pp. 33-9.

Saravi, B. et al., 2013. Discharge against medical advice in the pediatric wards in Boo-Ali Sina Hospital, Sari, Iran 2010. Acta Informatica Medica, 21(4), p. 253. [DOI:10.5455/ aim.2013.21.253-256]

Southern, W. N., Nahvi, S. \& Arnsten, J. H., 2012. Increased risk of mortality and readmission among patients discharged against medical advice. The American Journal of Medicine, 125(6), pp. 594-602. [DOI:10.1016/j.amjmed.2011.12.017]

Vahdat, S., Hesam, S. \& Mehrabian, F., 2010. Effective factors on patient discharge with own agreement in selected Therapeutic Training Centers of Ghazvin Shahid Rajaei. The Faculty of Nursing and Midwifery, Guilan Province, 20(2), pp. 47-52. 